\title{
PERFIL DOS DISCENTES (INGRESSANTES E CONCLUINTES) DE SECRETARIADO EXECUTIVO: UM ESTUDO COMPARATIVO NAS INSTITUIÇÕES DE ENSINO SUPERIOR (IES) PÚBLICAS
}

\section{EXECUTIVE SECRETARIAT STUDENTS' PROFILE (FRESHMEN AND SENIORS): A COMPARATIVE STYDY IN PUBLIC EDUCATION INSTITUTIONS}

\author{
Vania Souza Bilert \\ Mestranda em Desenvolvimento Regional da Universidade Tecnológica Federal do \\ Paraná - UTFPR \\ Professora do Curso de Secretariado Executivo da Universidade Estadual do \\ Oeste do Paraná - UNIOESTE \\ vaniabilert@hotmail.com
}

\section{Fabiana Veloso Biscoli}

Mestre em Administração pela Universidade Estadual de Londrina - UEL Professora da Universidade Estadual do Oeste do Paraná - UNIOESTE fbiscoli@yahoo.com.br 


\section{RESUMO}

O objetivo deste artigo é identificar o perfil dos discentes, ingressantes e concluintes, dos cursos de graduação em Secretariado Executivo. A pesquisa foi realizada com os discentes de 11 Instituições de Ensino Superior (IES) públicas brasileiras, estaduais e federais. O estudo configura-se como descritivoexploratório, fazendo parte da amostra 507 discentes, sendo 311 ingressantes e 196 concluintes. Os principais resultados indicam que os discentes atuam em empresas de diversos segmentos, com destaque ao comércio e prestação de serviços; $87 \%$ são do gênero feminino e a faixa etária predominante é entre 17 a 24 anos. Destaca-se, como fator positivo, a atuação profissional dos discentes desde o início da graduação, exercendo as atribuições pertinentes ao profissional de Secretariado Executivo, o que revela que os discentes conseguem relacionar o que é aprendido em sala de aula com a prática profissional, o que também evidencia a aceitação do empresariado pelos profissionais de Secretariado Executivo.

Palavras-chave: Perfil; Secretariado Executivo; Instituições de Ensino Superior (IES). 


\begin{abstract}
The objective of this paper is to identify the profile of beginner and graduate students who apply for Executive Secretariat graduation course. This research was carried out with students from 11 Brazilian public undergraduate schools, both federal and state ones. This is considered a descriptive and exploratory study, which analyzed 507 students, 311 beginners and 196 graduate ones. The main results show that students perform in different segment companies, but especially in service companies, $87 \%$ are female and the predominant age group is between 17 and 24 years old. In a positive way, this research stands out the factor that these students perform professionally since the beginning of the graduation, exerting the functions which are up to the Executive Secretariat professional. This reveals that the students are able to link what they have learned inside the classroom with the professional practice, which also highlights the acceptance of professionals of Executive Secretariat by the entrepreneurship.
\end{abstract}

Key-words: Profile; Executive Secretariat; Undergraduate Institutions. 


\section{INTRODUÇÃO}

Com as constantes mudanças no mercado de trabalho, a competitividade acirrada e a exigência de profissionais capacitados, vários setores da economia foram influenciados, entre eles o ensino superior. Esse argumento tem sustentado a necessidade de expansão dos cursos universitários em várias áreas, e os cursos que abordam a atuação profissional organizacional, aliado aos novos sistemas de gestão, têm-se destacado nessa nova performance mundial.

Com relação ao Brasil, nos últimos anos, observa-se um grande aumento do número de cursos superiores e Instituições de Ensino Superior (IES), o que facilitou o acesso ao terceiro grau. Por outro lado, uma preocupação igualmente crescente é a qualidade dos cursos ofertados por essas mesmas instituições. Com este crescimento acelerado, houve a necessidade de criação de instrumentos de avaliação dos cursos superiores e das IES, para a garantia da qualidade de formação oferecida.

Não obstante essa preocupação, as IES passaram a conhecer de maneira mais abrangente seu público-alvo, principalmente o que concerne ao perfil dos alunos, tais como gênero, estado civil, idade, escolaridade que possuíam ao ingressar no curso, segmentos e setores das empresas que atuam os discentes, ocupação/atividade profissional, a fim de melhor subsidiar estudos, tanto para os projetos dos cursos como para adequar metodologias, considerando-os como sujeitos de desenvolvimento.

A partir de tal perspectiva, é importante evidenciar que a profissão de secretariado executivo passou por mudanças ao longo dos anos - o que exigiu dos profissionais o desenvolvimento de um novo perfil profissional, direcionado às habilidades e competências necessárias para a atuação no competitivo mercado de trabalho. Desta forma, o interesse no tema vem ao encontro em identificar o perfil dos discentes e quais as principais mudanças ao longo de todo o curso.

Pretende-se, a partir deste cenário, compreender o perfil dos discentes do curso de Secretariado Executivo nas IES públicas brasileiras. Para isso, o procedimento dar-se-á por meio de um comparativo no perfil do corpo discente de onze instituições de ensino superior. 
Evidencia-se que a partir do diagnóstico do perfil do discente, com informações de dados básicos, é mais fácil compreender o que eles esperam, suas aspirações, valores, anseios; sendo suporte de informações aos cursos, para o desenvolvimento de atividades mais direcionas e atrativas, instrumentando os discentes para o competitivo mercado de trabalho.

Assim, o estudo objetiva apresentar o panorama do perfil do discente de Secretariado Executivo. Para tanto, propõe-se uma revisão teórica pautada na evolução do sistema de avaliação das IES, assim como se aponta o histórico dos cursos de graduação em Secretariado Executivo no Brasil. Na sequência, serão apontados os procedimentos metodológicos que levaram à formatação da pesquisa que buscou identificar nos cursos de Secretariado Executivo das IES brasileiras o perfil dos ingressantes e concluintes.

\section{OS CURSOS DE SECRETARIADO EXECUTIVO NO BRASIL}

As atividades de ensino do curso de Secretariado Executivo no Brasil tiveram início em 1969, pela Universidade Federal da Bahia. No entanto, na época, o curso era voltado para o ensino das técnicas secretariais. Nessa época as funções do profissional limitavam-se às atividades de datilografia, taquigrafia, arquivos e atendimento telefônico.

Ressalta-se que apesar do primeiro curso ter sido criado em 1969, foi no ano de 1978 que ocorreu o reconhecimento oficial do curso, e a primeira universidade a conseguir o reconhecimento foi a Universidade Federal de Pernambuco.

A partir da década de 1990, ocorreu a ampliação do número de cursos de Secretariado Executivo no país; também se destaca que um fator que contribuiu para esse crescimento foi a regulamentação da profissão, em 1985, através da lei n. 7.377/85 que definiu as atribuições para o técnico em secretariado e secretário executivo.

Para Nonato Júnior (2009, p. 14), "O crescimento do secretariado nas universidades teve o papel de divulgar a profissão, superar estigmas, alargar campo de trabalho e inaugurar um domínio acadêmico de atuação das assessorias".

Revista de Gestão e Secretariado, São Paulo, v. 2, n. 2, p.33-57, jul./dez. 2011. 
Em 2004 ocorreu uma ampliação significativa da oferta dos cursos de graduação em Secretariado Executivo no Brasil. As regiões Sul e Sudeste ofertaram respectivamente, $26,4 \%$ e $37,6 \%$, dos cursos de graduação em Secretariado Executivo. Nesse mesmo período, a região Centro-Oeste, Nordeste e Norte contribuíram respectivamente pela a oferta de $13,6 \%, 16 \%$ e $6,4 \%$ dos cursos superiores de Secretariado Executivo (PIÑOL; CASSIANO, 2004).

No entanto, com o aumento do número de cursos superiores em Secretariado Executivo e a exigência de profissionais preparados para atender a demanda do mercado de trabalho, em 2005 foram instituídas pelo ministério da educação, as Diretrizes Curriculares para os cursos de Secretariado Executivo, com o objetivo de padronizar o currículo de formação profissional nas instituições de ensino superior.

Com a regulamentação das Diretrizes Curriculares foi possível o reenquadramento dos Projetos Políticos Pedagógicos por parte das instituições que ofertavam o curso, direcionando-os para as competências e habilidades que se julgam necessárias para o perfil contemporâneo do profissional de Secretariado.

Destaca-se que ao longo dos 42 anos da criação do primeiro curso de Secretariado Executivo, paralelo às mudanças impostas pelo mercado de trabalho, também ocorreram grandes mudanças no perfil do corpo discente, seus objetivos e expectativas. Desta forma, conhecer o perfil dos discentes - objetivo deste artigo - torna-se fundamental, mas antes é necessário compreender o avanço do perfil profissional do secretário executivo.

\subsection{A EVOLUÇÃO DA PROFISSÃO DE SECRETÁRIO EXECUTIVO}

A profissão de secretário executivo tem suas origens na antiguidade, remetendo ao passado da época dos faraós, representado pelos escribas, e que na época tinha predominância masculina.

Com a Revolução Comercial, o advento tecnológico, e mais precisamente após as duas grandes guerras mundiais, a profissão de secretário passou a ter mais destaque na sociedade, principalmente pela falta de mão-de-obra 
masculina, o que deu oportunidade à entrada das mulheres no mercado de trabalho para o exercício da função de secretária.

No Brasil, a profissão começa a aparecer nas empresas na década de 1950, ressaltando que nas décadas de 1950 e 1960 o secretário passou a ser requisitado pelas empresas, mas suas funções limitavam-se ao exercício das técnicas secretariais. Nos anos 1970, aconteceram grandes mudanças para a profissão: o secretário passou a ter uma atuação mais dinâmica nas organizações, com mais respeito, passando a ser visto com um membro ativo na gerência (NATALENSE, 1998).

Os anos 1980 foram decisivos para a valorização profissional, ocorrendo mudanças na concepção do empresariado, com relação à visão do profissional secretário. Nessa época, a profissão foi regulamentada pela lei n. 7.277 de 30-91985, alterada em 10-1-1996 pela lei n. 9.261.

Em 1988, os profissionais de secretariado passaram a ser representado pela Fenassec (Federação Nacional de Secretárias e Secretários), que desde sua fundação objetiva principalmente a conscientização e valorização profissional. Ainda na década de 1980, mais precisamente em 1989, foi publicado oficialmente o código de ética profissional, para regular a moral e a conduta dos profissionais secretários executivos no exercício da profissão (CARVALHO, GRISON, 1998).

O novo perfil profissional, mais participante, consciente de sua postura e atribuições, além da necessidade do desenvolvimento de habilidades técnicas e comportamentais; começou a surgir a partir dos anos 1990, e permeia até os dias atuais.

É importante destacar que o novo perfil profissional conduziu a uma atuação além do exercício das técnicas secretariais e rotinas administrativas, como também à realização de atividades de gestão, consultoria, articulação da informação, empreendedorismo, além da assessoria executiva.

Desta forma, a multifuncionalidade da profissão também é uma característica muito valorizada pelo mercado de trabalho, pois permite ao profissional atuar em diversas áreas dentro de uma empresa.

Com as evidentes mudanças no que tange a exigência do mercado de trabalho, torna-se necessário conhecer o perfil dos discentes, para que a 
universidade possa melhor direcionar seus esforços na preparação dos acadêmicos ao exercício de suas atividades profissionais.

É importante destacar que, paralelo às mudanças no perfil dos discentes e à exigência do mercado de trabalho, ocorreram mudanças na formatação dos currículos dos cursos, e principalmente do sistema de avaliação; salienta-se que os processos avaliativos começaram a ter cada vez mais destaque, evidenciandose como um instrumento valioso de melhoria da qualidade do ensino.

\subsection{EVOLUÇÃO DO SISTEMA DE AVALIAÇÃO DAS IES}

O surgimento das avaliações de ensino superior relaciona-se com desenvolvimento das IES e dos cursos de graduação no Brasil, que estavam em franco desenvolvimento. Percebe-se que no decorrer dessa evolução histórica da educação no país, foi necessário iniciar um processo de avaliação da educação superior. As Universidades no Brasil começaram a surgir a partir de 1920. Nessa data foi fundada a primeira universidade brasileira, Universidade do Rio de Janeiro no Estado do Rio de Janeiro (STALLIVIERI, 2006).

A partir daquela década houve a intensa expansão das Instituições de Ensino Superior no país. De acordo com Stallivieri (2006 p. 4): "No período de trinta anos, compreendido entre 1930 (revolução industrial) e 1964 (governo militar assume o poder), foram criadas mais de 20 universidades federais no Brasil".

Na década de 1980 foram realizadas importantes reformas no Sistema de Educação Superior. Com o surgimento da era da globalização, a forte interação entre a educação e o mercado de trabalho, e a diversidade nos cursos de graduação proporcionou uma demanda competitiva (SINAES, 2004). Foi necessário então introduzir um sistema de avaliação que medisse a qualidade de ensino das instituições, e que fornecesse mérito e reconhecimento tanto para o curso de graduação como para a instituição.

Entre a década de 1980 a 1990 ocorreu um crescimento acelerado de artigos referentes à importância da avaliação dos cursos superiores. Surge, então, o primeiro sistema de avaliação dos cursos superiores: o Programa de Avaliação da Reforma Universitária (Paru), de 1983. O Paru aplicou questionários

Revista de Gestão e Secretariado, São Paulo, v. 2, n. 2, p.33-57, jul./dez. 2011. 
a docentes e acadêmicos os quais eram direcionados à mensuração da estrutura administrativa, à expansão das matrículas, à caracterização do corpo docente, à relação entre atividades de ensino, pesquisa e extensão, entre outras (SINAES, 2004).

Em 1985 surgiu o MEC, com uma proposta de avaliação da Educação Superior que utilizasse uma concepção regulatória, dando relevo a dimensões individuais, seja do alunado, seja dos cursos e instituições.
A partir dos anos 90, inicia uma quarta fase com a Constituição de 1988 e com a homologação de Leis que passaram a regular a educação superior. Havia a necessidade de flexibilização do sistema, redução do papel exercido pelo governo, ampliação do sistema e melhoria nos processos de avaliação com vistas à elevação da qualidade (SINAES, 2004, p. 18).

A partir da década de 1990 surge o Programa de Avaliação Institucional das Universidades Brasileiras - Paiub. Na etapa inicial aplicava uma autoavaliação que se estendia em toda instituição e terminava em uma avaliação externa. Embora sua experiência tenha sido curta, conseguiu dar legitimidade à cultura da avaliação e promover mudanças visíveis na dinâmica universitária (SINAES, 2004).

Com a interrupção do apoio do MEC ao Paiub, foi implementado outro programa de avaliação, o Exame Nacional de Cursos (ENC), o qual surge por meio da Lei n. 9.131/1995 e da Lei de Diretrizes e Bases da Educação Nacional Lei n. 9.394/1996. Era realizado por concluintes de cursos de graduação, sendo aplicado um questionário sobre as condições socioeconômicas do aluno e suas opiniões sobre as condições de ensino do curso frequentado (SINAES, 2004).

Após as tentativas de avaliação dos cursos superiores citados, surge em 2004 o Exame Nacional de Desempenho dos Estudantes, o Enade. O Enade foi instituído pela Lei no 10.861 de 14-4-2004, art. 50, e foi formulado com o objetivo de verificar as competências e habilidades básicas das áreas e dos conhecimentos sobre os conteúdos básicos e profissionalizantes (ENADE, 2006). Enquanto o antigo Exame Nacional de Cursos (ENC) aplicava a prova apenas uma vez a todos os estudantes, o Enade usa procedimentos amostrais, com alunos ingressantes e concluintes.

A avaliação do Enade leva em consideração o quanto a instituição de educação acrescenta aos estudantes ao longo do curso, ou seja, a mudança que permite verificar 0 efeito do curso sobre 0 
aprendizado do estudante, buscando evidenciar o que a IES agrega ao perfil cultural e profissional do aluno (ENADE, 2006, p. 36).

Ou seja, o Enade busca mensurar o desempenho do aluno ao longo da graduação. Ao avaliar o aluno no primeiro ano e no último ano do curso, o resultado deste exame mostra o nível do desenvolvimento de suas competências desde o início da graduação até sua formação (ENADE, 2006).

Nesse contexto, o principal objetivo é avaliar o desempenho do aluno. Mas tem como objetivo, também, avaliar as condições de ensino oferecidas pelas Instituições de Ensino Superior como a estrutura física fornecida para os alunos, o conteúdo programático; se este se encontra compatível com as Diretrizes Curriculares do curso, e a qualidade do corpo docente (ENADE, 2006).

Após o surgimento do ENADE, surge também em 2004, através da Lei $n$. 10.861 de 14-4, o Sistema Nacional de Avaliação da Educação Superior (Sinaes), sendo este parte integrante do mesmo.

O Sinaes tem por objetivo:

Assegurar o processo nacional de avaliação das instituições de
educação superior, dos cursos de graduação e do desempenho
acadêmico de seus estudantes, buscando a melhoria da qualidade
da educação superior, a orientação da expansão da sua oferta, o
aumento da eficácia institucional e a promoção do aprofundamento
dos compromissos e responsabilidades sociais das instituições de
educação superior, por meio da valorização de sua missão pública,
da promoção dos valores democráticos, do respeito à diferença e à
diversidade, da afirmação da autonomia e da identidade
institucional (SINAES, 2004).

Salienta-se que as avaliações obrigatórias que são realizadas nos cursos devem ser consideradas como um importante processo de assessoramento e para a análise de reformulação dos currículos, aspirando facilitar a definição do perfil de formação profissional, sendo necessária a familiaridade entre o que a instituição oferece e as exigências do mercado de trabalho.

As informações apresentadas evidenciam a acelerada expansão do ensino superior durante as últimas décadas e, principalmente, as mudanças no processo de avaliação dos cursos. No entanto, vale ressaltar que a expansão do ensino superior deve ocorrer de forma quantitativa e também qualitativa. 
Ao articular o desenvolvimento qualitativo, é necessário levar em conta o público das universidades, nesse caso, os acadêmicos, e principalmente entender que o processo de evolução deve ser pautado em propiciar melhores condições de aprendizagem, que só serão efetivamente concretizadas, se a universidade conhecer e refletir sobre o perfil do seu público.

\section{MÉTOdOS E TÉCNICAS DE PESQUISA}

A pesquisa tem como população as Instituições de Ensino Superior (IES) públicas que participaram em 2009, do Exame Nacional de Desempenho de Estudantes (Enade), de um total de dezoito instituições de ensino superior, obtiveram-se dados relativos a onze instituições, o que corresponde um retorno de $61,11 \%$ da amostra.

Este estudo se propôs analisar, de forma comparativa, o perfil dos discentes de onze Instituições de Ensino Superior (IES) públicas brasileiras, estaduais e federais. Destacam-se as seguintes IES participantes, na ordem como serão apresentadas na análise dos dados: Universidade Estadual de Maringá (UEM), Universidade Federal de Roraima (UFRR), Universidade Estadual de Santa Catarina (UFSC), Centro Universitário de União da Vitória (Uniuv), Universidade Estadual do Oeste do Paraná (Unioeste), Instituto Federal de Mato Grosso (IFMT), Universidade Estadual de Londrina (UEL), Universidade Federal da Paraíba (UFPB), Universidade Estadual do Centro Oeste (Unicentro), Universidade Federal de Sergipe (UFS) e Fundação Universidade Federal de Viçosa (UFV).

O estudo considerou como universo da pesquisa os discentes das instituições de ensino superior pública, matriculados no primeiro semestre de 2011. Desta forma, a amostra da pesquisa foi formada por todos os alunos presentes em sala de aula na data de aplicação dos questionários, o que totalizou 507 acadêmicos, sendo 311 acadêmicos ingressantes - ou seja, que estão cursando o primeiro ano do curso - e 196 acadêmicos concluintes. O curso do IFMT mesmo não tendo concluintes, por ser um curso que está no segundo ano de funcionamento, para melhor comparar o perfil está incluso no 
Perfil dos discentes (ingressantes e concluintes) de secretariado executivo: um estudo comparativo nas instituições de ensino superior (IES) públicas

cálculo da amostra, pois os acadêmicos deste segundo ano do curso responderam como concluintes.

A pesquisa pode ser caracterizada como exploratória, considerando-se que não foram identificados estudos que analisassem o perfil comparativo de Instituições de Ensino Superior Pública que ofertam a graduação de Secretariado Executivo.

Classifica-se como pesquisa descritiva e de campo, já que descreve a situação a partir de dados primários, pois além de revelar o perfil dos discentes aspira ao desenvolvimento de novos estudos.

A amostra da pesquisa é classificada segundo Campos (2000), como não probabilística acidental, pois todos os elementos da população não possuem a mesma probabilidade estatística de serem incluídos na amostra.

Como instrumento para coleta de dados optou-se pelo questionário semiestruturado, em que os alunos que estiveram presentes em sala de aula, nos meses de maio a julho, participaram da pesquisa. Ressalte-se que a escolha deste período deve-se por concentrar maior quantidade de alunos em sala de aula, devido às atividades acadêmicas de finalização do semestre.

A análise das variáveis foi qualitativa que, para Roesh (1999), argumentase que pesquisa qualitativa e seus métodos de coleta e análise de dados são apropriados para uma ênfase exploratória da pesquisa.

Após terem sido coletados os dados, processados e obtidos os resultados, estes foram analisados e discutidos. Para melhor apresentação dos resultados, utilizou-se a forma comparativa entre as IES, conforme será apresentado no próximo capítulo.

\section{APRESENTAÇÃO E ANÁLISE DOS RESULTADOS}

A apresentação dos resultados abordará cada item pesquisado, dividido em ingressantes e concluintes, seguido da análise descritiva dos dados coletados.

A Tabela 1 apresenta a distribuição dos acadêmicos por ano do curso: 
Vania Souza Bilert \& Fabiana Veloso Biscoli

Tabela 1 - Distribuição dos acadêmicos

\begin{tabular}{|c|c|c|c|c|c|c|c|c|c|c|c|c|}
\hline & \multicolumn{11}{|c|}{ UNIVERSIDADE } & \multirow[b]{3}{*}{ TOTAL } \\
\hline & & & & & & & & & & & & \\
\hline & UEM & UFRR & UFSC & UNIUV & $\begin{array}{l}\text { UNIO } \\
\text { ESTE }\end{array}$ & IFMT & UEL & UFPB & $\begin{array}{l}\text { UNICE } \\
\text { NTRO }\end{array}$ & UFS & UFV & \\
\hline Ingressantes & 27 & 25 & 19 & 20 & 33 & 22 & 31 & 45 & 31 & 35 & 23 & 311 \\
\hline Concluintes & 27 & 19 & 18 & 11 & 29 & 23 & 19 & 9 & 20 & 9 & 12 & 196 \\
\hline TOTAL & 54 & 44 & 37 & 31 & 62 & 45 & 50 & 54 & 51 & 44 & 35 & 507 \\
\hline
\end{tabular}

A amostra, em termos de distribuição dos acadêmicos, aponta para um número maior de ingressantes, destacando o alto número de ingressantes na UFPB (Universidade Federal da Paraíba), com 45 ingressantes e apenas 9 concluintes, e a UFS (Universidade Federal do Sergipe), com 35 ingressantes e 9 concluintes. Visando caracterizar o perfil da amostra, na Tabela 2 pode ser observado o gênero dos acadêmicos de Secretariado Executivo das IES.

Tabela 2 - Gênero dos respondentes

\begin{tabular}{|l|l|l|l|l|l|l|l|l|l|l|l|c|c|}
\hline & \multicolumn{10}{|c|}{ UNIVERSIDADE } & TOTAL \\
\hline Ingressantes & UEM & UFRR & UFSC & UNIUV & $\begin{array}{l}\text { UNIO } \\
\text { ESTE }\end{array}$ & $\begin{array}{l}\text { IFM } \\
\text { T }\end{array}$ & $\begin{array}{l}\text { UE } \\
\text { L }\end{array}$ & UFPB & $\begin{array}{l}\text { UNICEN } \\
\text { TRO }\end{array}$ & UFS & UFV & TOTAL \\
\hline Masculino & 1 & 6 & 3 & 9 & 3 & 4 & 1 & 3 & 4 & 5 & 7 & $\mathbf{4 6}$ \\
\hline Feminino & 26 & 19 & 16 & 11 & 30 & 18 & 30 & 42 & 27 & 30 & 16 & $\mathbf{2 6 5}$ \\
\hline Concluintes & \multicolumn{10}{|c|}{ Fonte: Dados da pesquisa. } \\
\hline Masculino & 1 & 0 & 7 & 2 & 4 & 1 & 2 & 2 & 0 & 0 & 2 & $\mathbf{2 1}$ \\
\hline Feminino & 26 & 19 & 11 & 9 & 25 & 22 & 17 & 7 & 20 & 9 & 10 & $\mathbf{1 7 5}$ \\
\hline
\end{tabular}

Observe-se que a maioria dos acadêmicos é do gênero feminino, apresentando um percentual de $87 \%$ do total de ingressantes e concluintes.

É importante evidenciar os dados apontados pelos ingressantes da UNIUV, que possui nove acadêmicos do sexo masculino e onze do sexo feminino.

Com relação aos concluintes destaca-se a UFSC, com sete acadêmicos do sexo masculino e onze do sexo feminino, e também se evidencia a UFRR, Unicentro e UFS, que não possuem nenhum homem no perfil dos concluintes.

Ressalta-se como fator positivo que o perfil dos acadêmicos de Secretariado Executivo está se modificando; há alguns anos era composto basicamente por mulheres, e atualmente percebe-se que os homens estão deixando de lado o estereótipo de que o Secretariado Executivo é profissão feminina e estão escolhendo o curso pela formação profissional. 
Perfil dos discentes (ingressantes e concluintes) de secretariado executivo: um estudo comparativo nas instituições de ensino superior (IES) públicas

A próxima tabela apresenta o estado civil dos respondentes.

Tabela 3 - Estado civil dos respondentes

\begin{tabular}{|l|l|l|l|l|l|l|l|l|l|l|l|l|c|}
\hline \multicolumn{10}{|c|}{ UNIVERSIDADE } \\
\hline Ingressantes & UEM & UFRR & UFSC & UNIUV & $\begin{array}{l}\text { UNIO } \\
\text { ESTE }\end{array}$ & IFMT & UEL & UFPB & $\begin{array}{l}\text { UNICEN } \\
\text { TRO }\end{array}$ & UFS & UFV & TOTAL \\
\hline Casado & 0 & 9 & 3 & 0 & 5 & 2 & 2 & 10 & 6 & 0 & 0 & $\mathbf{3 7}$ \\
\hline Solteiro & $\mathbf{2 7}$ & $\mathbf{1 5}$ & $\mathbf{1 5}$ & $\mathbf{2 0}$ & $\mathbf{2 8}$ & $\mathbf{1 8}$ & $\mathbf{2 9}$ & $\mathbf{3 4}$ & $\mathbf{2 3}$ & $\mathbf{3 3}$ & $\mathbf{2 3}$ & $\mathbf{2 6 5}$ \\
\hline Divorciado & 0 & 0 & 1 & 0 & 0 & 0 & 0 & 1 & 1 & 0 & 0 & $\mathbf{3}$ \\
\hline Concluintes \\
\hline $\mathbf{9}$
\end{tabular}

Fonte: Dados da pesquisa.

Conforme foi apurado na tabulação dos dados, o estado civil, para $81 \%$ da amostra, inclusos os ingressantes e concluintes, é evidenciado como solteiro. Ressalta-se que, na atualidade, os jovens estão dando prioridade ao planejamento de carreira, deixando o casamento em segundo plano.

Outro item diagnosticado foi a idade dos respondentes. Os resultados podem ser visualizados na Tabela 4.

Tabela 4 - Idade dos respondentes

\begin{tabular}{|c|c|c|c|c|c|c|c|c|c|c|c|c|}
\hline \multirow[b]{2}{*}{ Ingressantes } & \multicolumn{12}{|c|}{ UNIVERSIDADE } \\
\hline & UEM & UFRR & UFSC & UNIUV & $\begin{array}{l}\text { UNIO } \\
\text { ESTE }\end{array}$ & IFMT & UEL & UFPB & $\begin{array}{l}\text { UNICEN } \\
\text { TRO }\end{array}$ & UFS & UFV & TOTAL \\
\hline 17 a 20 anos & 23 & 9 & 4 & 13 & 21 & 13 & 19 & 10 & 16 & 19 & 20 & 167 \\
\hline 21 a 24 anos & 3 & 9 & 7 & 4 & 7 & 3 & 10 & 21 & 5 & 6 & 1 & 76 \\
\hline 25 a 28 anos & 1 & 4 & 3 & 2 & 4 & 3 & 1 & 8 & 3 & 9 & 2 & 40 \\
\hline $\begin{array}{l}\text { Acima de } 28 \\
\text { anos }\end{array}$ & 0 & 3 & 5 & 1 & 1 & 3 & 1 & 6 & 7 & 1 & 0 & 28 \\
\hline \multicolumn{13}{|l|}{ Concluintes } \\
\hline 17 a 20 anos & 6 & 1 & 0 & 2 & 7 & 10 & 2 & 0 & 2 & 0 & 1 & 31 \\
\hline 21 a 24 anos & 16 & 6 & 6 & 8 & 15 & 4 & 11 & 1 & 11 & 1 & 10 & 89 \\
\hline 25 a 28 anos & 4 & 7 & 4 & 0 & 6 & 2 & 4 & 6 & 6 & 4 & 1 & 44 \\
\hline $\begin{array}{lll}\text { Acima } \\
\text { anos }\end{array}$ & 1 & 5 & 8 & 1 & 1 & 7 & 2 & 2 & 1 & 4 & 0 & 32 \\
\hline
\end{tabular}

Fonte: Dados da pesquisa.

De acordo com a Tabela 4, verifica-se que a faixa etária dos ingressantes concentra-se entre 17 a 20 anos, seguido da faixa etária entre 21 a 24 anos. Já

Revista de Gestão e Secretariado, São Paulo, v. 2, n. 2, p.33-57, jul./dez. 2011. 
para os concluintes a faixa etária concentra-se entre 21 a 24 anos, seguido de 25 a 28 anos. Assim, esse resultado condiz se somados os quatro anos em média de duração do curso.

Evidencia-se que os jovens estão ingressando cada vez mais cedo no ensino superior, o que ressalta que cada vez mais a educação superior deve ser retratada também como um instrumento que dá oportunidade ao discente de construir sua formação não só profissional, mas também de adquirir maturidade pessoal.

Outro dado do perfil dos discentes ingressantes e concluintes está relacionado à escolaridade que já possuíam antes de ingressar no curso, constante na Tabela 5:

Tabela 5 - Escolaridade dos respondentes

\begin{tabular}{|c|c|c|c|c|c|c|c|c|c|c|c|c|}
\hline \multirow[b]{2}{*}{ Ingressantes } & \multicolumn{12}{|c|}{ UNIVERSIDADE } \\
\hline & UEM & UFRR & UFSC & UNIUV & $\begin{array}{l}\text { UNIO } \\
\text { ESTE } \\
\end{array}$ & IFMT & UEL & UFPB & $\begin{array}{l}\text { UNICEN } \\
\text { TRO } \\
\end{array}$ & UFS & UFV & TOTAL \\
\hline Ensino Médio & 24 & 15 & 8 & 15 & 24 & 14 & 24 & 39 & 26 & 30 & 20 & 239 \\
\hline $\begin{array}{l}\text { Curso Superior } \\
\text { Completo }\end{array}$ & 0 & 2 & 3 & 1 & 3 & 3 & 0 & 1 & 0 & 1 & 1 & 15 \\
\hline $\begin{array}{l}\text { Curso Superior } \\
\text { Incompleto }\end{array}$ & 2 & 1 & 6 & 1 & 2 & 0 & 4 & 3 & 4 & 2 & 3 & 28 \\
\hline Curso Técnico & 3 & 7 & 7 & 3 & 7 & 6 & 5 & 4 & 7 & 2 & 3 & 54 \\
\hline Outro & 0 & 0 & 1 & 0 & 1 & 1 & 5 & 0 & 0 & 0 & 0 & 8 \\
\hline \multicolumn{13}{|l|}{ Concluintes } \\
\hline Ensino Médio & 25 & 14 & 8 & 11 & 24 & 7 & 11 & 5 & 17 & 5 & 10 & 137 \\
\hline $\begin{array}{l}\text { Curso Superior } \\
\text { Completo }\end{array}$ & 0 & 1 & 7 & 0 & 0 & 4 & 1 & 2 & 0 & 1 & 0 & 16 \\
\hline $\begin{array}{l}\text { Curso Superior } \\
\text { Incompleto }\end{array}$ & 2 & 3 & 2 & 0 & 2 & 1 & 2 & 1 & 1 & 1 & 2 & 17 \\
\hline Curso Técnico & 0 & 2 & 3 & 0 & 3 & 12 & 5 & 0 & 3 & 2 & 0 & 30 \\
\hline Outro & 0 & 0 & 0 & 0 & 0 & 0 & 2 & 1 & 0 & 0 & 0 & 3 \\
\hline
\end{tabular}

Fonte: Dados da pesquisa.

Destaca-se, conforme a Tabela 5, que 54 discentes ingressaram no Secretariado Executivo já com uma formação técnica, 28 discentes possuíam ensino superior incompleto, enquanto que 15 discentes possuem o curso superior completo. 
Solicitou-se aos respondentes que indicassem o nome do curso que fizeram anteriormente, a fim de se obter a informação sobre quem seria o candidato que se mostrou interessado em cursar Secretariado Executivo.

Evidencia-se, com relação ao curso técnico apontado por 54 discentes, que o Técnico em Secretariado é a qualificação mais procurada, no qual 13 discentes já haviam cursado antes de ingressar no curso superior de Secretariado Executivo, seguido do curso Técnico em Administração, apontado por nove discentes, seis discentes já tinham cursado o Técnico em Informática, quatro o Técnico em Enfermagem, três discentes afirmaram que cursaram Tecnologia em Sistema de Informação, três o Técnico Segurança do Trabalho, dois discentes cursaram o Técnico em Alimentos, dois o Técnico em Fotografia, e os demais cursos apresentaram somente um discente em cada, sendo: Técnico em Agrimensura, Técnico em Edificações, Técnico em Hospedagem, Técnico em Administração e Produção Industrial, Técnico em Recursos Humanos, Técnico em Auxiliar Administrativo, Técnico em Prótese Dentária, Técnico em Contabilidade, Técnico Pedagógico, Técnico em Farmácia, Técnico em Hotelaria e Hospedagem, Magistério e Formação de docentes.

Também buscou-se identificar o discente que optou por Secretariado Executivo após ter passado por outra experiência no ensino superior. Destacamse os cursos que 28 discentes ingressantes iniciaram e desistiram: quatro discentes desistiram de Administração, três de História, dois discentes desistiram de Pedagogia, dois de Jornalismo, dois desistiram de Letras, dois de Turismo, seguido de um discente em cada curso: Publicidade, Hotelaria, Biblioteconomia, Serviço Social, Psicologia, Desenho Industrial, Matemática, Antropologia, Letras Inglês, Educação Física, Direito, Fisioterapia, Biomedicina.

Evidencia-se que quinze discentes classificados como ingressantes, já possuíam outra graduação completa antes de cursar Secretariado Executivo, sendo que três discentes são graduados em Administração, dois em Pedagogia, seguidos de um discente em cada curso, sendo: Contabilidade, Serviço Social, Publicidade, Logística, Direito, Biologia, Letras Português, Zootecnia, Letras.

Outro item constatado pela pesquisa é que dos discentes concluintes, trinta ingressaram no Secretariado Executivo e já possuíam alguma formação 
técnica, dezesseis discentes possuem o curso superior completo, enquanto que dezessete discentes destacaram possuir o ensino superior incompleto.

Destaca-se que trinta discentes já tinham formação em algum curso técnico. O curso técnico mais apontado pela pesquisa foi o Técnico em Secretariado com dez discentes, seguido do Técnico em Administração e o técnico em Gestão em Secretariado ambos com quatro discentes, Técnico em Informática com três discentes, e dois possuem o Técnico em Turismo, seguido de um discente em cada curso que segue: Técnico em Telecomunicações, Técnico em Contabilidade, Técnico Eletrônica, Técnico em Química, Técnico em Auxiliar Administrativo, Técnico em Hotelaria.

Ressalta-se também que dois discentes citaram cursar o magistério e o normal Pedagógico, sendo cursos subsequentes.

Com relação aos discentes concluintes cabe destacar que dezesseis ingressaram no Secretariado com outro curso superior completo, destacando dois discentes que cursaram Administração, dois em Ciências Contábeis, dois são graduados em Pedagogia, dois em Letras e os demais cursos apresentaram um discente em cada, sendo: Comunicação, Tecnologia da Informação, Letras/Alemão, Educação Física, Turismo, Psicologia, História, Filosofia e Tecnólogo em Secretariado.

E por fim evidenciam-se os cursos superiores que os discentes concluintes iniciaram e desistiram, sendo o total de dezessete discentes: dois desistiram de Psicologia, dois de Administração, dois de Pedagogia, dois de Direito, os demais cursos apresentaram somente um discente em cada, sendo: Geografia, Ciências Contábeis, Serviço Social, Publicidade e Propaganda, Engenharia da Pesca, Biologia, Recursos Humanos, Física.

Outro item pesquisado é a ocupação/atividade profissional atual dos respondentes, conforme dados da Tabela 6.

Verificou-se com relação aos respondentes ingressantes, que 112 são funcionários de empresa privada, seguidos de 103 discentes que são estudantes. Os resultados também demonstraram que, com relação aos concluintes, 69 são funcionários de empresas privadas e 65 discentes são estagiários.

Cabe destacar que o perfil se modifica com o passar dos anos, no $1^{0}$ ano $33 \%$ do total da amostra dos acadêmicos ingressantes é estudante, e no 40 ano a maioria já está atuando em empresas públicas ou privadas ou estagiam. No 
Perfil dos discentes (ingressantes e concluintes) de secretariado executivo: um estudo comparativo nas instituições de ensino superior (IES) públicas

entanto, considera-se o diagnóstico positivo, pois um alto número de ingressantes já está em contato com a prática profissional.

Tabela 6 - Ocupação/atividade profissional atual dos respondentes

\begin{tabular}{|c|c|c|c|c|c|c|c|c|c|c|c|c|}
\hline \multirow{2}{*}{ Ingressantes } & \multicolumn{12}{|c|}{ UNIVERSIDADE } \\
\hline & UEM & UFRR & UFSC & UNIUV & UNIOESTE & IFMT & UEL & UFPB & \begin{tabular}{|l|} 
UNICEN \\
TRO
\end{tabular} & UFS & UFV & TOTAL \\
\hline $\begin{array}{l}\text { Negócio } \\
\text { próprio }\end{array}$ & 0 & 1 & 0 & 1 & 1 & 0 & 1 & 2 & 0 & 0 & 0 & 6 \\
\hline $\begin{array}{l}\text { Funcionário } \\
\text { empresa } \\
\text { privada }\end{array}$ & 12 & 7 & 10 & 11 & 15 & 6 & 14 & 14 & 12 & 11 & 0 & 112 \\
\hline $\begin{array}{l}\text { Funcionário } \\
\text { público }\end{array}$ & 1 & 2 & 0 & 0 & 0 & 1 & 0 & 5 & 1 & 3 & 1 & 14 \\
\hline Autônomo & 0 & 3 & 0 & 1 & 0 & 2 & 0 & 2 & & 2 & 0 & 10 \\
\hline Estagiário & 1 & 5 & 7 & 5 & 6 & 10 & 10 & 0 & 10 & 1 & 3 & 58 \\
\hline Bolsista & 1 & 1 & 1 & 0 & 0 & 0 & 0 & 0 & 1 & 0 & 1 & 5 \\
\hline Estudante & 12 & 6 & 1 & 2 & 11 & 3 & 4 & 22 & 6 & 18 & 18 & 103 \\
\hline Outro & 0 & 0 & 0 & 0 & 0 & 0 & 2 & 0 & 1 & 0 & 0 & 3 \\
\hline
\end{tabular}

\section{Concluintes}

\begin{tabular}{|l|l|l|l|l|l|l|l|l|l|l|l|c|}
\hline Negócio próprio & 0 & 0 & 1 & 0 & 1 & 0 & 1 & 1 & 0 & 0 & 0 & $\mathbf{4}$ \\
\hline $\begin{array}{l}\text { Funcionário empresa } \\
\text { privada }\end{array}$ & 11 & 3 & 8 & 7 & 12 & 8 & 6 & 4 & 6 & 3 & 1 & $\mathbf{6 9}$ \\
\hline Funcionário público & 2 & 5 & 2 & 1 & 6 & 3 & 0 & 4 & 1 & 2 & 0 & $\mathbf{2 6}$ \\
\hline Autônomo & 0 & 1 & 0 & 0 & 1 & 1 & 0 & 0 & 0 & 1 & 0 & $\mathbf{4}$ \\
\hline Estagiário & 12 & 7 & 4 & 1 & 4 & 9 & 11 & 1 & 7 & 2 & 7 & $\mathbf{6 5}$ \\
\hline Bolsista & 0 & 0 & 1 & 0 & 0 & 0 & 0 & 1 & 0 & 0 & 0 & $\mathbf{2}$ \\
\hline Estudante & 2 & 3 & 2 & 2 & 2 & 2 & 0 & 0 & 6 & 0 & 4 & $\mathbf{2 3}$ \\
\hline Outro & 0 & 0 & 0 & 0 & 3 & 0 & 1 & 0 & 0 & 2 & 0 & $\mathbf{6}$ \\
\hline
\end{tabular}

Fonte: Dados da pesquisa.

Revista de Gestão e Secretariado, São Paulo, v. 2, n. 2, p.33-57, jul./dez. 2011. 
Ainda de acordo com a Tabela 6, dez respondentes do total de ingressantes e concluintes possuem negócio próprio, fator que comprova que o empreendedorismo está crescente nos discentes de Secretariado Executivo.

Outro fator apontado pela pesquisa, é que do total de 311 ingressantes, $179(57,56 \%)$ classificam-se como estagiário, autônomo, bolsista, estudante e os que assinalaram a opção "outro"; desta forma apenas 132 (42,44\%) possuem trabalho efetivo ou são empreendedores; enquanto que para os concluintes do total de 196, apenas 96 (48,98\%) encontram-se nessa classificação, o que destaca que mais da metade $(51,02 \%)$ dos concluintes já possuem trabalho efetivo ou são empreendedores.

A Tabela 7 identificou o segmento de empresa que os acadêmicos atuam.

Tabela 7 - Segmento da empresa onde trabalham os respondentes

\begin{tabular}{|c|c|c|c|c|c|c|c|c|c|c|c|c|}
\hline \multirow{2}{*}{ Ingressantes } & \multicolumn{12}{|c|}{ UNIVERSIDADE } \\
\hline & UEM & UFRR & UFSC & UNIUV & $\begin{array}{l}\text { UNIO } \\
\text { ESTE }\end{array}$ & IFMT & UEL & UFPB & $\begin{array}{l}\text { UNICEN } \\
\text { TRO }\end{array}$ & UFS & UFV & TOTAL \\
\hline Comércio & 7 & 5 & 3 & 2 & 7 & 3 & 4 & 11 & 6 & 8 & 0 & 56 \\
\hline Indústria & 2 & 4 & 1 & 8 & 5 & 0 & 2 & 0 & 3 & 1 & 1 & 27 \\
\hline Prestação de serviços & 7 & 6 & 13 & 6 & 11 & 11 & 20 & 12 & 15 & 8 & 5 & 114 \\
\hline Terceiro Setor & 0 & 2 & 1 & 0 & 0 & 0 & 0 & 0 & 1 & 0 & 0 & 4 \\
\hline Órgão público & 1 & 2 & 0 & 2 & 0 & 4 & 0 & 0 & 0 & 0 & 0 & 9 \\
\hline Outro & 0 & 1 & 0 & 0 & 0 & 0 & 0 & 1 & 0 & 0 & 0 & 2 \\
\hline \multicolumn{13}{|l|}{ Concluintes } \\
\hline Comércio & 3 & 1 & 2 & 3 & 7 & 2 & 1 & 2 & 4 & 2 & 0 & 27 \\
\hline Indústria & 1 & 0 & 0 & 3 & 5 & 0 & 1 & 1 & 0 & 1 & 0 & 12 \\
\hline Prestação de serviços & 16 & 12 & 13 & 2 & 9 & 18 & 14 & 5 & 7 & 4 & 1 & 101 \\
\hline Terceiro Setor & 2 & 0 & 2 & 0 & 2 & 1 & 3 & 0 & 1 & 0 & 0 & 11 \\
\hline Órgão público & 4 & 2 & 0 & 1 & 3 & 1 & 0 & 1 & 2 & 2 & 7 & 23 \\
\hline Outro & 0 & 1 & 0 & 0 & 0 & 0 & 0 & 0 & 0 & 0 & 0 & 1 \\
\hline
\end{tabular}

Fonte: Dados da pesquisa.

Como pode ser visto na Tabela 7, tanto para os ingressantes, como para os concluintes, a prestação de serviços representa o segmento de atuação mais procurado, seguido do comércio. Cabe destacar que a prestação de serviço inclui também as instituições de ensino - o que a pesquisa apresentou como sendo o segmento da prestação de serviços que mais concentra os discentes - também 
Perfil dos discentes (ingressantes e concluintes) de secretariado executivo: um estudo comparativo nas instituições de ensino superior (IES) públicas

se evidencia que este segmento teve um grande crescimento nos últimos anos, o que indica excelentes oportunidades profissionais para os que nele atuam.

Complementando a informação da Tabela 7, apresenta-se na Tabela 8, os setores das empresas de atuação dos discentes.

De acordo com a Tabela 8, tanto para os ingressantes, como para os concluintes, a recepção/atendimento é o setor com o maior número de atuação dos discentes, seguido da assessoria de gerência e direção. Ao analisar os apontamentos da recepção/atendimento tem-se uma relação com as atribuições das atividades técnicas, no entanto, com os resultados da assessoria/gerência, verifica-se que os acadêmicos estão exercendo a atribuição pertinente ao secretário executivo, no que tange as atividades de assessoria. Ressalta-se também que desde o primeiro ano do curso, o discente já tem o contato com a prática profissional, fator muito relevante para o desenvolvimento da profissão, o que representa uma evolução na concepção do empresariado, com relação às atribuições do profissional.

Tabela 8 - Setor da empresa onde atuam os respondentes

\begin{tabular}{|c|c|c|c|c|c|c|c|c|c|c|c|c|}
\hline \multirow[b]{2}{*}{ Ingressantes } & \multicolumn{12}{|c|}{ UNIVERSIDADE } \\
\hline & UEM & UFRR & UFSC & UNIUV & UNIOESTE & IFMT & UEL & UFPB & $\begin{array}{l}\text { UNICEN } \\
\text { TRO }\end{array}$ & UFS & UFV & TOTAL \\
\hline $\begin{array}{l}\text { Recepção/ } \\
\text { atendimento }\end{array}$ & 8 & 8 & 8 & 7 & 13 & 5 & 14 & 3 & 13 & 6 & 3 & 88 \\
\hline $\begin{array}{l}\text { Assessoria } \\
\text { gerência/ } \\
\text { direção }\end{array}$ & 1 & 3 & 6 & 0 & 1 & 4 & 8 & 3 & 3 & 1 & 1 & 31 \\
\hline $\begin{array}{l}\text { Recursos } \\
\text { humanos }\end{array}$ & 0 & 1 & 2 & 1 & 1 & 2 & 0 & 2 & 0 & 0 & 0 & 9 \\
\hline $\begin{array}{ll}\text { Compras } & \text { e } \\
\text { financeiro }\end{array}$ & 1 & 1 & 1 & 1 & 1 & 1 & 1 & 1 & 2 & 2 & 1 & 13 \\
\hline $\begin{array}{ll}\text { Vendas } & \mathrm{e} \\
\text { marketing } & \\
\end{array}$ & 3 & 1 & 1 & 1 & 1 & 1 & 0 & 7 & 1 & 2 & 0 & 18 \\
\hline Administrativo & 0 & 1 & 1 & 0 & 2 & 1 & 4 & 0 & 1 & 0 & 0 & 10 \\
\hline Secretaria & 0 & 1 & 0 & 0 & 0 & 0 & 0 & 0 & 1 & 0 & 0 & 2 \\
\hline Educação & 2 & 1 & 0 & 1 & 0 & 0 & 0 & 2 & 1 & 0 & 0 & 7 \\
\hline Outro & 2 & 2 & 2 & 8 & 4 & 4 & 4 & 3 & 2 & 4 & 1 & 36 \\
\hline \multicolumn{13}{|l|}{ Concluintes } \\
\hline $\begin{array}{l}\text { Recepção/ } \\
\text { atendimento }\end{array}$ & 12 & 4 & 9 & 5 & 8 & 10 & 11 & 0 & 6 & 5 & 3 & 73 \\
\hline $\begin{array}{l}\text { Assessoria } \\
\text { gerência/ } \\
\text { direção }\end{array}$ & 6 & 9 & 4 & 0 & 5 & 8 & 7 & 5 & 5 & 1 & 4 & 54 \\
\hline $\begin{array}{l}\text { Recursos } \\
\text { humanos }\end{array}$ & 2 & 1 & 1 & 0 & 3 & 3 & 0 & 0 & 1 & 2 & 1 & 14 \\
\hline
\end{tabular}

Revista de Gestão e Secretariado, São Paulo, v. 2, n. 2, p.33-57, jul./dez. 2011. 
Vania Souza Bilert \& Fabiana Veloso Biscoli

\begin{tabular}{|l|l|l|l|l|l|l|l|l|l|l|l|c|}
\hline $\begin{array}{l}\text { Compras e e } \\
\text { financeiro }\end{array}$ & 2 & 1 & 3 & 2 & 1 & 0 & 2 & 0 & 3 & 1 & 0 & 15 \\
\hline $\begin{array}{l}\text { Vendas enarketing } \\
\text { e }\end{array}$ & 0 & 1 & 2 & 1 & 3 & 0 & 1 & 0 & 2 & 1 & 0 & $\mathbf{1 1}$ \\
\hline Administrativo & 3 & 0 & 0 & 0 & 6 & 0 & 0 & 0 & 0 & 0 & 0 & 9 \\
\hline Secretaria & 0 & 0 & 1 & 0 & 1 & 0 & 0 & 0 & 0 & 0 & 0 & $\mathbf{2}$ \\
\hline Educação & 0 & 0 & 0 & 0 & 0 & 2 & 1 & 3 & 0 & 0 & 0 & $\mathbf{6}$ \\
\hline Outro & 4 & 1 & 1 & 1 & 4 & 1 & 0 & 1 & 1 & 0 & 2 & 16 \\
\hline
\end{tabular}

Fonte: Dados da pesquisa

Ressalta-se, conforme dados da Tabela 8, que os discentes atuam em vários setores, em sua maioria, relacionados com a área de formação do curso.

Além dos setores apontados na tabela, outros setores foram descritos pelos discentes ingressantes na opção "outro", sendo: operacional/produção citado por nove respondentes, dois trabalham com confecção de roupas, destacando-se discentes atuantes em setores de projetos, informática, construção, massagem e limpeza de pele, eventos, apoio técnico, artes, orientador social, serviços gerais, manutenção, merendeira, digitadora, suporte e ações voluntárias.

Para os acadêmicos concluintes, evidenciou-se que dois discentes atuam no departamento de licitação, destacando-se também discentes que atuam na editoração, digitação, saúde no trabalho, produção, analista, auxiliar de cartório, patrimônio, logística, divisão de jornalismo e ambiental.

Buscou-se ainda identificar a faixa salarial dos acadêmicos, a fim de comparar a realidade das várias regiões do país, destacando que em todos os casos os respondentes pesquisados enfrentam realidade semelhante a de estudantes de IES pública.

Na Tabela 9, será verificada a renda dos acadêmicos.

Tabela 9 - Média salarial dos respondentes

\begin{tabular}{|c|c|c|c|c|c|c|c|c|c|c|c|c|}
\hline \multirow[b]{2}{*}{ Ingressantes } & \multicolumn{12}{|c|}{ UNIVERSIDADE } \\
\hline & UEM & UFRR & UFSC & UNIUV & $\begin{array}{l}\text { UNIO } \\
\text { ESTE }\end{array}$ & IFMT & UEL & UFPB & $\begin{array}{l}\text { UNICEN } \\
\text { TRO }\end{array}$ & UFS & UFV & TOTAL \\
\hline $\begin{array}{l}\mathrm{R} \$ 300,00 \\
\mathrm{R} \$ 500,00\end{array}$ & 4 & 6 & 4 & 6 & 4 & 5 & 5 & 9 & 3 & 8 & 3 & 57 \\
\hline $\begin{array}{l}\mathrm{R} \$ 500,00 \\
\mathrm{R} \$ 700,00\end{array}$ & 6 & 7 & 3 & 4 & 13 & 10 & 12 & 7 & 14 & 7 & 0 & 83 \\
\hline
\end{tabular}


Perfil dos discentes (ingressantes e concluintes) de secretariado executivo: um estudo comparativo nas instituições de ensino superior (IES) públicas

\begin{tabular}{|l|l|l|l|l|l|l|l|l|l|l|l|c|}
\hline $\begin{array}{l}\mathrm{R} \$ 700,00 \\
\mathrm{R} \$ 900,00\end{array}$ & 4 & 2 & 3 & 5 & 2 & 1 & 5 & 4 & 5 & 0 & 0 & $\mathbf{3 1}$ \\
\hline $\begin{array}{l}\mathrm{R} \$ 900,00 \\
\mathrm{R} \$ 1.200,00\end{array}$ & 1 & 0 & 4 & 2 & 2 & 2 & 3 & 2 & 2 & 2 & 1 & $\mathbf{2 1}$ \\
\hline $\begin{array}{l}\text { Acima } \\
\mathrm{R} \$ 1.200,00\end{array}$ & 0 & 4 & 4 & 0 & 1 & 1 & 3 & 0 & 0 & 0 & 1 & $\mathbf{1 4}$ \\
\hline Outro & 0 & 0 & 0 & 1 & 0 & 0 & 0 & 0 & 0 & 0 & 0 & $\mathbf{1}$ \\
\hline Concluintes \\
\hline $\begin{array}{l}\mathrm{R} \$ 300,00 \\
\mathrm{R} \$ 500,00\end{array}$
\end{tabular}

Fonte: Dados da pesquisa.

Verificou-se que tanto para os discentes ingressantes como para os concluintes, a renda entre $\mathrm{R} \$ 500,00$ a $\mathrm{R} \$ 700,00$ foi a que predominou; no entanto, a segunda faixa salarial mais apontada para os ingressantes foi a renda entre $R \$ 300,00$ e $R \$ 500,00$; enquanto que para os concluintes a segunda maior incidência ficou entre $R \$ 900,00$ e $R \$ 1.200,00$. Este resultado evidencia que a média salarial dos discentes aumenta durante a graduação, o que condiz com os esforços despendidos no decorrer da graduação, em consonância com as expectativas dos acadêmicos na busca de crescimento profissional e financeiro.

\section{CONSIDERAÇÕES FINAIS}

Este artigo teve como objetivo inicial traçar o perfil dos discentes ingressantes e concluintes de cursos de Secretariado Executivo das IES Públicas. Como resultado do estudo, constatou-se que, mesmo apesar do grande avanço da profissão, o gênero feminino ainda reproduz o maior público. No entanto, um fator positivo é que os homens estão aos poucos ingressando na profissão.

É importante destacar a idade dos discentes, que se concentra na faixa etária entre 17 a 24 anos, o que denota que os jovens estão buscando preparação para o mercado de trabalho, e dedicando-se primeiramente à 
carreira, pois os resultados apontam que a grande maioria é de solteiros. Isso pode ser reflexo das políticas de governo de incentivo à criação de cursos superiores a partir de 1990, permitindo maior acesso ao ensino superior aos jovens, que podem dar continuidade à sua formação logo após a conclusão do ensino médio.

Constatou-se também que antes de ingressar no curso de Secretariado muitos acadêmicos iniciaram outra graduação e desistiram, o que pode ser relacionado com o grande número de cursos universitários ofertados e também porque os jovens têm de decidir cada vez mais cedo os rumos da carreira.

Também se verificou que o Secretariado Executivo está sendo a escolha de alguns jovens, que já possuem uma graduação e que devido à formação generalista do curso, acabam escolhendo o Secretariado Executivo.

Outro aspecto revelado pela pesquisa é que no primeiro ano do curso grande parte dos discentes já está no mercado de trabalho, em empregos efetivos ou estágios, o que aproxima o aluno da realidade das organizações e auxilia no desenvolvimento de competências e habilidades - sendo assim, os alunos trabalham durante o dia e estudam à noite -; no entanto este fator impossibilita o aluno a um maior envolvimento com a universidade, projetos e pesquisas.

Com relação às atividades profissionais constatou-se maior incidência de atuação dos discentes em empresas do comércio e na prestação de serviço, exercendo atividades relacionadas com a formação do curso. Outro detalhe importante apontado pela pesquisa é que a renda dos discentes aumenta no decorrer do período de graduação.

Neste sentido salienta-se que cada vez mais as Instituições de Ensino Superior (IES) necessitam proporcionar ao futuro profissional uma formação que assegure sua competitividade no mercado de trabalho, com o desenvolvimento de habilidades, e que garanta a inserção profissional, o que necessita de um ensino pautado pela qualidade. Para o discente é importante aproveitar a graduação para construir conhecimentos para que possam melhorar suas condições econômicas e financeiras na qual se encontra e assumir o papel de agente de mudança.

Embora o presente estudo apresente limitações, pode servir de base para o desenvolvimento e aprofundamento de outros estudos sobre o tema, visando 
diagnosticar o perfil dos discentes de Secretariado Executivo nas universidades e faculdades, tanto públicas quanto privadas, a fim de ampliar a pesquisa para apurar um panorama mais amplo deste discente.

\section{REFERÊNCIAS}

CAMPOS, Luiz Fernando de Lara. Métodos e técnicas de pesquisa em psicologia. Campinas, São Paulo: Alínea, 2000.

CARVALHO, Antonio Pires; GRISSON, Diller (orgs.). Manual do Secretariado Executivo. São Paulo: D 'Livros, 1998.

ENADE - Exame Nacional de Desempenho dos Estudantes - Relatório Síntese de Secretariado Executivo. Brasília, DF, 2006

NATALENSE, Maria Liana Castro. Secretária Executiva: manual prático. São Paulo: IOB, 1998.

NONATO JÚNIOR, Raimundo. Epistemologia e teoria do conhecimento em Secretariado Executivo: a fundação das ciências da assessoria. Fortaleza, PE: Editora Expressão Gráfica, 2009.

PIÑOL, Susana Taulé.; CASSIANO, Reinaldo Mesquita. Secretariado Executivo: Expansão do curso e perfil dos alunos em Rondonópolis - MT. IV Colóquio Internacional sobre Gestão Universitária na América do Sul, Florianópolis, SC, 2004.

ROESCH, Sylvia Maria Azevedo. Projetos de estágio e de pesquisa em administração. São Paulo: Atlas, 1999.

SINAES, Sistema Nacional de Avaliação da Educação Superior - Da Concepção à regulamentação. 2a ed. ampliada. Brasília, DF, 2004. 
STALLIVIERI, Luciane. O sistema de ensino superior do Brasil, características, tendências e perspectivas.

Disponível

em

<http://www.ucs.br/ucs/tplCooperacaoCapa/cooperacao/assessoria

/artigos/sistema_ensino_superior.pdf.> Acesso em: 26 out.2009. Caxias do Sul, RS, 2006.

Data do recebimento do artigo: 09/09/2011

Data do aceite de publicação: 05/12/2011

Revista de Gestão e Secretariado, São Paulo, v. 2, n. 2, p.33-57, jul./dez. 2011. 